\title{
Understanding the right to health and food for the type 2 diabetic patient
}

\begin{abstract}
The rights to food and health are fundamentals human rights expressed on the international covenant on economic, social and cultural rights of the United Nations (ICESCR). Both rights advocate for people to live in optimal conditions, however gaps in opportunities to health care access, availability or access to healthy foods and adequate housing to live a life with dignity are obstacles for achieving the expression of these rights. This article aims to discuss in understandable way, what are the most influential factors for the achieving of these rights for type 2 diabetic patients. Social determinants of health and ethics and policies are discussed in the article in a brief, concise manner to introduce care givers, health care practitioners and community leaders related to health on what is important outside of health care system, to be taken into account when addressing and taking care of type 2 diabetic patients. The elevated economic and psychological costs of suffering this disease, justify to make an effort in order to prevent the onset and complications of those at risk, by understanding the human rights of these patients and the policies to be implemented to achieve this goal.
\end{abstract}

Keywords: type 2 diabetes, right to health, right to food, social determinants of death
Volume 4 Issue 5 - 2017

\author{
Marianella Herrera Cuenca \\ Chair of the Department Development and Health, Central \\ University of Venezuela (UCV), SA
}
Correspondence: Marianella Herrera-Cuenca,Associate Professor and Researcher Center for Development Studies (CENDES), Chair of the Department Development and Health, Central University of Venezuela (UCV), SA, Email manyma@gmail.com

Received: May 01, 2017 | Published: September 15, 2017

\section{Introduction}

The right to health and food are fundamental and basic human rights, and are well established by the international covenant on economic, social and cultural rights of the United Nations (ICESCR). ${ }^{1}$ The article number eleven of the ICESCR states: "The States Parties to the present Covenant recognize the right of everyone to an adequate standard of living for himself and his family, including adequate food, clothing and housing, and to the continuous improvement of living conditions"; and the article twelve of the same covenant recognizes the "right of everyone to the highest attainable standard of physical and mental health". ${ }^{1}$ As a global society, there is now a deeper and comprehensive knowledge of what is the meaning of the human right to health and the challenge is how these standards are to be applied in practice. ${ }^{2}$ Diabetes Mellitus describes a group of metabolic disorders characterized by increased blood glucose concentration, and people living with diabetes have a higher risk of morbidity and mortality than general population. ${ }^{3}$ Type 2 Diabetes in particular is relevant because it is related to living conditions, lifestyle and its prevention is achievable, thus diminishing the cost (economic and psychological) of the disease. Type 2 diabetes, accounts for $90-95 \%$ of all diabetes. This form include individuals who have insulin resistance and usually relative insulin deficiency. Most patients, but not all patients with type 2 diabetes are overweight or obese, in consequence, management of excess weight through appropriate diet and exercise interventions are key for the prevention of its onset. ${ }^{4}$

According to the International Diabetes Federation (IDF) data, in 2015 , it was estimated that there were 415 million people with diabetes aged 20-79years, 5.0million deaths attributable to diabetes, and the total global health expenditure due to diabetes was estimated at 673 billion US dollars; $75 \%$ of those with diabetes were living in low and middle income countries. By 2040 the number of people with diabetes is expected to increase to 642 million. ${ }^{3}$ The world Health Organization (WHO) Commission on the Social Determinants of Health concluded that "the social conditions in which people are born, live and work are the single most important determinants of good health or ill health, of a long and productive life, or a short and miserable one". ${ }^{5}$ Governments and societal factors should work along to guarantee that living conditions are the best in order that citizens achieve the maximum development of the potential they have in order to live a good and productive life. It seems logical then, that access to a healthy diet, opportunities for exercising and the availability of the medicines, if necessary are to be guaranteed to type 2 diabetes patients in order to prevent the disease onset or delay its complications. The many and complex interactions between different social determinants of health have been approached by many researchers, authors and reports. Among the most relevant social determinants that impact over diseases such as: obesity, type 2 diabetes and cardiovascular diseases are: the socioeconomic position (SEP), access to health care, culture and residential environment. Gaps between social groups exist as social inequalities define, as an example, whether a person is able to access a job that allows them to have a good salary that in consequence will promote an adequate standard of life or have access to a quality health care, or buy healthier foods or is able to jog in a safe environment. ${ }^{5} \mathrm{All}$ of the above has made the environment in which an individual live, an important platform for achieving a good quality of life, whether people live in a house that is safe and hygienically adequate or in a slum, and/or if they have access to food because it is available and it can be afforded, or the individuals are able to make healthier choices because they have the freedom to materialize their choices. ${ }^{6}$

In consequence, it is reasonable to think about the social determinants of health as key elements in preventing type 2 diabetes at low cost and delay the onset if possible of the disease, and avoid the complications such as: cardiovascular disease, blindness, renal failure and microvascular foot disease, all of which have an elevated cost not only economic but emotional and psychological for the individuals who suffers and their families. ${ }^{6}$ In addition to all the previous statements, an interesting discussion can be developed on how to define: "adequate nutrition" and "adequate food intake" since many 
of the programs that address hunger in the developing world aim to be adequate in caloric consumption, while nutrients intake might be still impaired because foods rich in calories (used in many programs) are cheaper and empty in nutrients than healthier ones. ${ }^{7,8}$ On the other hand: What are the factors that influence people's food choices, or why people can or cannot access some foods? How physical activity practice can be performed in good and safe neighborhoods, whereas insecure areas have low physical activity among the neighbors. ${ }^{5}$ Regarding these issues, in spite of the conditions people live in or the opportunities they all have had, why some individuals choose what they choose? It might be a possibility that their capabilities and particularly health agency will influence the promotion of good health for individuals, and the values people have related to health. ${ }^{9}$ Thus, there might be a reason for choosing what they choose. People will eat better and will perform adequate amounts of physical activity if they value those principles as lifestyle benefits that ensure good health in general. Both principles have been related to the prevention of type 2 diabetes or the delay of its onset. ${ }^{7}$ There is little research until the best of our knowledge about translating the statements of the human rights to food and health to type 2 diabetes patients specifically. Those human rights are key particularly for those suffering the disease in the developing world, where environmental conditions might be adverse. The aim of this article is to review some interactions of social factors that guarantee the right to health and to food in type 2 diabetic patients or those who are at risk of developing type 2 diabetes, in a way that can fill the basic need for understanding the essentials human rights for those who work in hospitals, are community care givers and or individuals at risk.

\section{The social determinants of health}

According to the WHO, the social determinants of health (SDOH) are the conditions, in which people are born, grow, work, live, and age, and the wider set of forces and systems shaping the conditions of daily life. These forces and systems include economic policies and systems, development agendas, social norms, social policies and political systems. ${ }^{10}$ Human's health starts at home, at school, in the neighborhood, at workplaces. ${ }^{10}$ And maintaining good health status requires good and adequate nutrition, a fair amount of physical activity, management of stress and enough sleep hours. Thus, income for a decent living, a safe housing and neighborhood, are essential for wellbeing. Programs such as Healthy People in the United States aims to incorporate the Social Determinants of Health in order to provide guidance for public policies and interventions for achieving the wellbeing of the population (Figure 1). ${ }^{11}$

When addressing prevention of diseases nowadays it is important to consider the influence that social factors have on the incidence, treatment and outcomes of diseases. Particularly for type 2 diabetes, issues such as lifestyle, education and access to quality health care services are factors that influence the prevention, delay the onset on those at risk or ensure a better quality of life on those who already have been diagnosed. ${ }^{4} \mathrm{An}$ important factor that has been demonstrated as a potential risk for developing and worsening diabetes is living in a food insecure household. What is food security? According to the United Nations for Food and Agriculture (FAO) food security is related to the availability of food, its access, the bioavailability and the permanent existence of the previous factors. ${ }^{12}$ Many governments have made statements and laws for guaranteeing the access to quality food for the population. As we consider the recognition of the States Parties on the eleven article of the ICESCR, we understand that the right to food is an important human right for all individuals and particularly for those whose inherited risks or situation makes them vulnerable to develop type 2 diabetes. Whether the environment promotes the intake of quality food or not, whether the individual can afford them and whether the choices are the right ones are the tools people have to achieve a good nutrition status that is consistent with good health. ${ }^{3,7}$ Access to quality care is the other key determinant for achieving good health status, at least on traditional perspective. However people in general seek, as Jennifer Prah says: good health and the ability to pursue it. ${ }^{9}$ So preventive health services might be at the intersection with health promotion and education, treatment strategies, health strategies and care choices and many more that constitute the social environment that in optimal conditions is the path toward good health. ${ }^{6,10}$

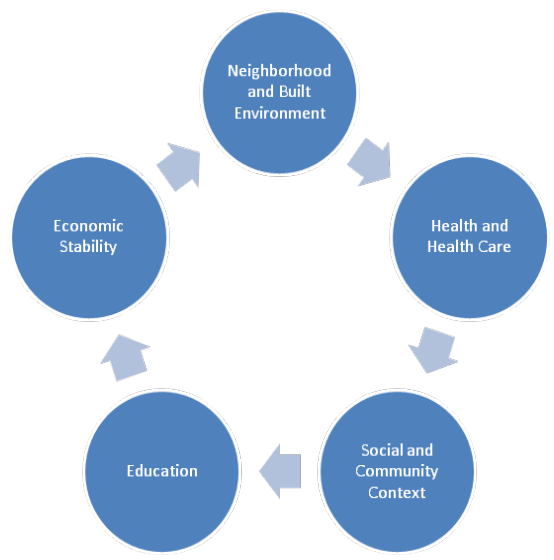

Figure I SDOH, Social Determinants of Health. Source, Healthy People 2020.

https://www.healthypeople.gov/2020/topics-objectives/topic/socialdeterminants-of-health

\section{Ethics and policies}

The debate about what is fair and what is not, what should be the optimal situation for achieving good health and adequate nutrition status exists long ago. Good health as the end value, and for our purposes, living without type 2 diabetes, needs to balance not only the impact of the health determinants outside the health-care system (social determinants of health) and health system functioning ${ }^{9,13}$ but the actions to be taken to promote health. Traditional perspectives focused on the health systems as a mean to obtain health, were challenged by the theories that include social determinants of health as important key factors in achieving health. The John Rawls theory of justice where it is stated that justice requires the fair distribution of primary goods that are allocated to individuals through the "natural lottery" and "social lottery" of life $\mathrm{e}^{13,14}$ force us to re-think the need for diminishing the existing gaps between different social groups.

As per living without type 2 diabetes, the need for an environment that promotes a healthy life style is mandatory, thus guaranteeing the right to health access and adequate food should be rights derived from the lessons learned from all the scientific research trajectory about the evolution of this disease and the interactions between environmental conditions and the onset of the disease. The fact that some people have the opportunity to take care for prevention or treatment of the disease whereas other people are diagnosed at a late stage of the disease is a challenge for policy makers, health care community, families and individuals. What should be the approach for ameliorating this gaps, has been the central discussion at several levels: scientific, social and 
policy. Governments should, from a policy perspective, implement social strategies that aim to reduce inequalities, such as investing in basic education, affordable housing, and other forms of anti poverty policies. ${ }^{13}$ To reinforce this, the United Nations agenda for a sustainable global development, address that eradicating poverty in all its forms is the biggest challenge for a sustainable development. ${ }^{15}$ In this process eliminating hunger is key, as stated by the UN declaration, ${ }^{15}$ and as understood by the scientific principles, a step action toward the prevention of type 2 diabetes. ${ }^{4}$

\section{Discussion}

Without any doubt a good environment that promotes a healthy lifestyle is key in the prevention and control of type 2 diabetes. Thus, people should have the opportunity to access good and healthy food and a safe environment that allows and promotes physical activity and stress management. However, the right to health is controversial and many of the perspectives can be on the philosophical and ethics sides, while still go through the intersection of multidisciplinary analyses of medical ethics, international relations, international human rights law, health policy, public policies ${ }^{16}$ and implementation of education regarding the key components of type 2 diabetes needed to avoid any complications that might deteriorate the quality of life., ${ }^{4,6}$ The report from World Health Organization on Global health Risks, have identified six risk associated with noncommunicable diseases as the leading global risk factors for death: high blood pressure, tobacco use, high blood glucose levels, physical inactivity, overweight or obesity and high cholesterol levels. ${ }^{17}$ Trends over the last decades indicate that chronic non communicable diseases continue to grow and the risk factors, are on the rise. ${ }^{18}$ It is then important to recognize that inequalities in the access to health care or difficulties in the access to good food, and create the foundation for developing the characterization of social risks factors associated with the onset of type 2 diabetes, because nutrition status and wellbeing might be impaired. ${ }^{5,18-20}$

The right to food goes deeply into four dimensions introduced by FAO as part of the food security concept, almost three decades ago, include for everybody at all times
a. Access to food that is
b. Available
c. with appropriate bio-availability and
d. Consistency of all of the above. ${ }^{12}$

Regarding our case of the type 2 diabetic patient, not being able to access the appropriate and healthy foods might compromise the achievement of preventing the onset of this disease, or worse, it might well direct the individual toward the complications. In addition, not being able to access the health care system, being diagnosed and obtaining the proper treatment, would make any person vulnerable if at risk of disease. ${ }^{4}$

In general, people seek both: good health and the ability to pursue it, as Prah Ruger states. ${ }^{9}$ Also, Prah develops an approach that captures those called health capability, which integrates health outcomes and health agency. Applying these concepts to diabetes is challenging as it is expected to be in any chronic health disease. Why people, in spite to know they should eat healthy foods sometimes do not? Why people needing medicines sometimes do not get to comply a treatment, knowing it is for good? People might need adequate food and might not be able to buy it, because lack of income enough for healthy foods, or people might have enough money to buy but they will not. Why is that? How can States and Governments guarantee the rights to health and food? And, is that a State and/or Government duty? Or a combination of State providing the means to ensure a quality health system and developing health capabilities of individuals so they can obtain the ability to achieve health goals they value and act as agents of their own health?. ${ }^{9}$ For guaranteeing the rights to health and food of the type 2 diabetic population, the interaction of the means and the end values seems the path to achieve health on the long term. The mean (health resources and good food) and the end value: being healthy, should be based on social fairness, equality and the existence of the conditions for all to be able to be healthy., ${ }^{9,16,19,20}$ Enough social fairness should be one part of the equation of the achievement of health, while the other should be the empowerment of the individual capabilities in order to create the value of health.

\section{Conclusion}

The prevention of the onset of diabetes is a goal that is important for the population at risk. So guaranteeing the existence the conditions for all to be healthy combined with the own individuals responsibility to achieve health, be aware of what his/her goals to achieve a good life and value this goal seems the path for a transition from paternalism to autonomy. The challenge is then to apply policies that contribute to a fair prevention and/or control that might reduce for all the elevated cost not only economical but psychological of type 2 diabetes and its complications.

\section{Acknowledgements}

None.

\section{Conflict of interest}

Author declares that there is no conflict of interest.

\section{References}

1. United Nations Human Rights Office of the High Commissioner. International covenant on social, cultural and economic rights. 2015.

2. Toebes B, Ferguson R, Markovic MM, et al. Editors the Right to Health. A Multi-Country Study of Law, Policy and Practice. Hague, Netherlands, Europe: Asser Press; 2014. p. 1-472.

3. Ogurtsova K, da Rocha Fernandes JD, Huang Y, et al. IDF Diabetes Atlas: Global estimates for the prevalence of diabetes for 2015 and 2040. Diabetes Res Clin Prac. 2017;128:40-50.

4. American Diabetes Association. Standard of Medical Care in Diabetes. Diabetes Care. 2016;28(Supp 1):S4-S36.

5. World Health Organization. Closing the gap in a generation: health equity through action on the social determinants of health. Geneva, Switzerland; 2008.

6. Havranek EP, Mujahid MS, Barr DA, et al. Social Determinants of Risk and Outcomes for Cardiovascular Disease. A Scientific Statement from the American Heart Association. Circulation. 2015;132(9):873-898.

7. Drenowsky A, Spencer SE. Poverty and Obesity: the role of energy density and energy costs. Am J Clin Nutr. 2004;79(1):6-16.

8. Landaeta-Jiménez M, Herrera-Cuenca M, Ramírez G, et al. La Alimentación de los Venezolanos. (ENCOVI). In Venezuela: Vivir a Medias Encuesta Nacional de Condiciones de Vida 2015 in Anitza Fritez, AB Universidad Católica Andrés Bello (UCAB) Ediciones, Caracas, Venezuela; 2016. 71-89p. 
9. Prah Ruger J. Health Capability: Conceptualization and Operacionalization. Am J Public Health. 2010;100(1):41-49.

10. World CSDH. Closing the gap in a generation: health equity through action on the social determinants of health. Final Report of the Commission on Social Determinants of Health, Geneva, Switzerland; 2008.

11. Healthy People 2020. Social Determinants of Health, Rockville. Maryland, USA; 2016.

12. World Food Summit. Food and Agriculture Organization of the United Nations. Rome, Italy; 1996.

13. Prah Ruger J. Ethics of the Social determinants of health. Lancet. 2004;364(9439):1092-1097.

14. Rawls J. A Theory of Justice. Cambridge, Massachusetts: Harvard University Press; 1971.
15. Transforming our world: the 2030 Agenda for Sustainable Development. New York: United Nations Organization; 2015.

16. Prah Ruger J. Toward a Theory of a Right to Health: Capability and Incompletely Theorized Agreements. Yale Journal of Law \& the Humanities. 2006;18(2):273-280.

17. World Health Organization Global Health Risks. Mortality and burden disease attributable to selected major risks. Geneva, Switzerland; 2009.

18. Narayan KMV, Ali KM, Koplan JP. Global Noncommunicable Diseases, Where the Worlds Meet. N Engl J Med. 2010;363(13):1196-1198.

19. Herrera-Cuenca M, Castro J, Mangia K, et al. Are Social Inequities the Reason for the Increase in Chronic Non Communicable Diseases? A Systematic Review. J Diabetes Metab Disord Control. 2014;1(3):00017.

20. Popkin B, Duffey K, Gordon-Larsen P. Environmental influences on food choice, physical activity and energy balance. Physiol Behav. 2005;86(5):603-613. 